\title{
Arterial blood supply of the atrioventricular node and main bundle
}

a

\author{
- L. G. Van der Hauwaert, R. Stroobandt, and L. Verhaeghe \\ - From the Department of Anatomy and the Hartcentrum, St. Raphael University Clinic, \\ Leuven, Belgium
}

The arterial blood supply of the AV node and main bundle has been studied in 10 normal hearts. In each heart 150 to 200 histological sections of the $A V$ node region were analysed and the findings

1 correlated with magnified postmortem angiograms. This enabled determination of the origin of the supplying artery, the ramus septi fibrosi, and its ramifications within the node. In all hearts the

ramus septi fibrosi originated from the right coronary artery. Its course appears to be less constant and anatomically less closely related to the specific conducting tissue than that of the sinus node artery. In most hearts the artery entered the dorsal margin of the node, made a sharp caudal turn (50 to 90 degrees) approximately in the middle of the node, and penetrated again into the adjacent myocardium. Usually only a small branch continued the original course in the longitudinal axis towards the main bundle. The relatively poor blood supply of the main bundle was further shown by planimetric measurements of the arterial and arteriolar lumina. The arterial density was approximately Io times greater in the dorsal part of the node than in the main - bundle. Collateral blood supply was studied by injection of the left coronary artery. No direct anastomoses between the penetrating septal branches of the left anterior descending artery and the ramus septi fibrosi could be outlined. It is concluded that, from the viewpoint of blood supply, the main bundle and the ventral third of the AV node are more vulnerable than the dorsal part. This finding is correlated with some clinical studies in patients with $A V$ block complicating acute - myocardial infarction.

Five years after Tawara's discovery of the atrioventricular node, Haas (I9I I) gave a detailed description of the blood supply of the conducting system in the human, canine, and bovine heart. In an earlier report, Keith and Flack (1906) had mentioned the existence of $\rightarrow$ a branch of the right coronary artery which, from the dorsal interventricular groove, penewrated into the AV node. Mönckeberg (1908) also had noted an artery in this region but he - considered it to be inconstant and irregular in course. To designate this branch and to stress the close relation to the membranous inter- ventricular septum, Haas used the term arteria or ramus septi fibrosi. Later on it has also - Eeen called the artery of Haas. Gross (I92I) stated that the ramus septi fibrosi arose in 90

- per cent of the cases from the right coronary artery and that it supplied not only the AV node but also the main -bundle and the posterior fibres of the left bundle. In recent years Received 14 February 1972.

* In receipt of a grant from the Fonds voor Wetenschappelijk Geneeskundig Onderzoek.
James revived the interest in this part of the coronary circulation. He presented additional information about the blood supply of the conducting system (James and Burch, I958; James, 1962) and, in pathological conditions, attempted to correlate clinical and electrocardiographic findings with obstructive lesions of specific arteries (James, 1965, I969).

With the exception of Haas' original work, which included histological examination, previous studies are confined to a description of the origin and gross anatomy of the ramus septi fibrosi. By means of $x$-ray microscopy, Clarke (1965) investigated the other end of the arterial tree, namely the precapillary arterioles and capillaries. This method allows a fair estimation of the density of small vessels within a given area but is inappropriate to trace the continuity of arteries and arteriolar ramifications. In order to fill this gap, a morphological study, based on a combination of postmortem coronary angiography and serial histology, was carried out. Particular attention was paid to the course of the ramus septi 
fibrosi in relation to the specific AV conducting tissue and the arterial density in various parts of the system.

\section{Material and method}

Ten hearts, free from any discernible lesion at necropsy, were examined. The patients were between 6 and 70 years of age. The method has already been described in more detail (Verhaeghe and Van der Hauwaert, 1967). After cannulation of the coronary arteries, contrast material was injected by hand at controlled pressure of 60 to 90 $\mathrm{mmHg}$ and a temperature of $37^{\circ} \mathrm{C}$. A suspension of $60 \mathrm{~g}$ barium sulphate (Alubar Wander), $3 \mathrm{~g}$ gelatine, and $100 \mathrm{ml}$ water, was used. This medium, with a mean particulate diameter of $2 \mu \mathrm{m}$, penetrates uniformly to precapillary arterioles of about $20 \mu \mathrm{m}$. Stereoscopic films of the entire heart were taken in various incidences on Gevaert Structurix $\mathrm{D}_{2}$ plates. Close inspection of the preparation and the $x$-ray exposures made it possible to trace the origin of the ramus septi fibrosi and to follow its general course. When visible, the U-turn (James, I962) was a useful landmark. The free atrial and ventricular walls were removed and $x$-ray pictures were made of the interatrial and interventricular septa. Exposures of the region of the AV node and bundle were 5 to ro times magnified. Subsequently this part of the preparation was fixed. The block containing the AV conducting tissue was serially sectioned at $7 \mu \mathrm{m}$, perpendicular to the base of the membranous septum. Every Ioth section was stained with haematoxylin, eosin, and safranin, or with Masson trichrome. As the block was sectioned the remaining part of it was $x$-rayed at intervals of approximately $2 \mathrm{~mm}$. These pictures and the corresponding sections were given numbers and used as points of reference when the histological slides were correlated with the coronary angiogram. For this purpose the magnified radiographs of the AV node region were used as a framework. Vertical lines, corresponding to the numbered reference sections, were drawn on this 'map'. By means of these points of reference all arteries and large arterioles, visible on the $x$-ray pictures, were easily identified in the histological sections. In each particular section the borders of the node were accurately localized and, by means of a micrometer, measured in relation to the lumina of arteries and arterioles. The thus defined borders of the specific tissue were transferred to the magnified 'map' of the coronary system. Some 150 to 200 sections of each heart were examined. This time-consuming technique seemed to be the only way to determine exactly which coronary arteries were lying inside or outside the node and to trace all ramifications up to precapillary level. The final result was a series of three-dimensional reconstruction drawings, showing the coronary system of the AV node and bundle (Fig. I, 2, and 3).

The density of the arterial blood supply was estimated in a quantitative study. For every heart 6 transverse sections were analysed: 3 equally distributed in the longitudinal axis of the node and 3 equally distributed in the main bundle. From dorsal to ventral, the sections were marked A, B, C, D, E, and F. In each section the total cross-sectional area of the arterial and arteriolar lumina was planimetrically measured, summedup, and expressed as a percentage of the total surface of the node or bundle. The main purpose of this analysis was to compare the vascular density in various parts of the AV conducting system.

FIG. I Lateral view of the interventricular septum, after opacification of the coronary arteries. The free atrial and ventricular walls have been removed. The right circumflex coronary artery and the posterior descending artery are seen to the left. The ramus septi fibrosi and the $A V$ node region are indicated by a white arrow.

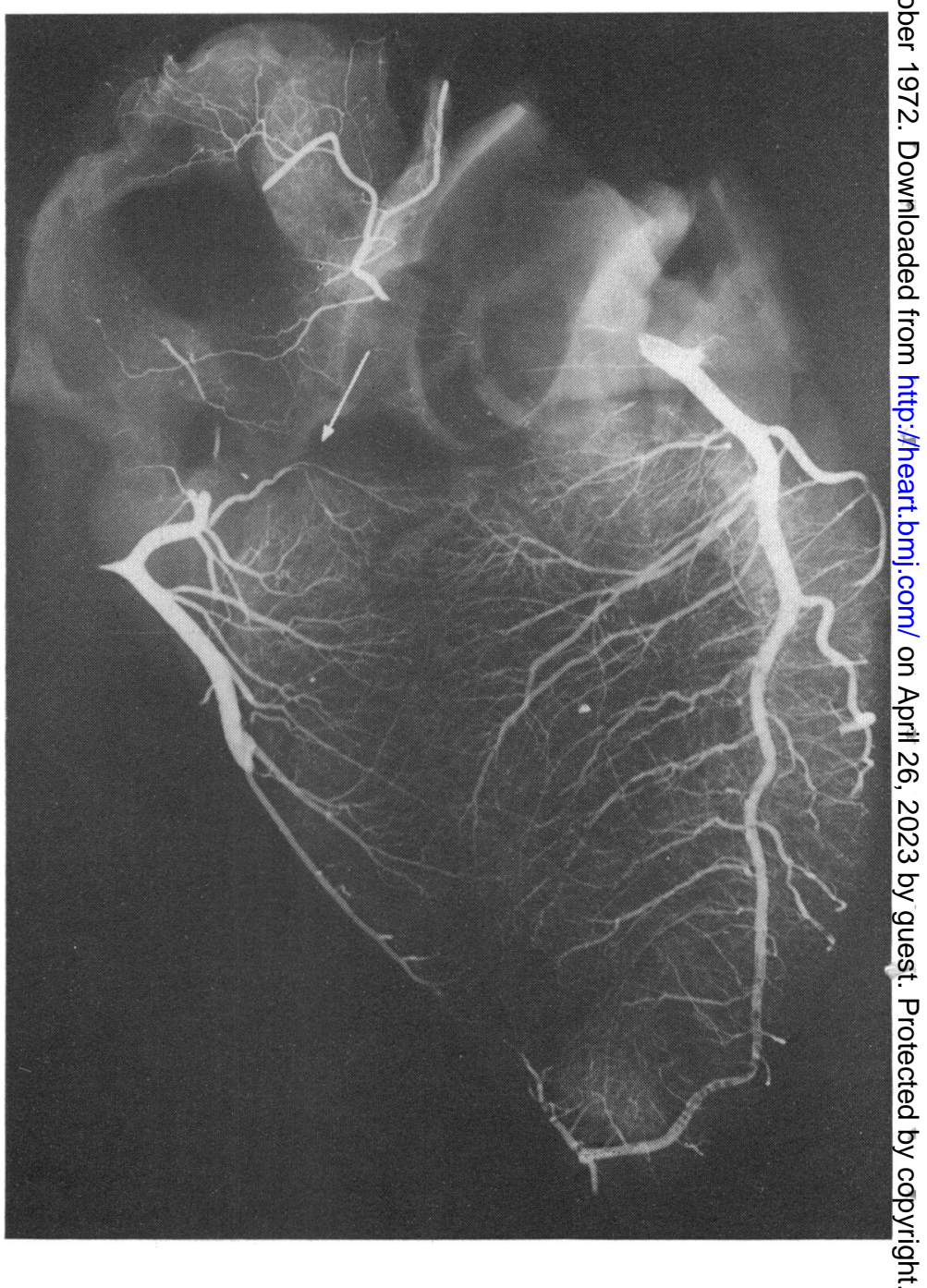


Finally, it was attempted to show collateral circulation to the region of the AV node. In 7 other normal hearts, in which the ramus septi fibrosi was a branch of the right coronary artery,

- only the left coronary artery was injected. Collateral circulation was studied on stereoscopic $x$-ray films.

\section{Results}

From reconstructive drawings of the AV conducting system in Io normal human hearts, it

- appears that the shape and size of the AV node and main bundle are less geometrical

a and constant than those of the sinus node. In most cases the node is a flattened, triangular, or trapezoid structure. The mean thickness 1 was $0.8 \mathrm{~mm}$ (range 0.55 to $\mathrm{I} \cdot 2 \mathrm{~mm}$ ), the average length in dorsoventral direction $4.3 \mathrm{~mm}$

- (range 3.1 to $5.7 \mathrm{~mm}$ ), and the average height, measured in atrioventricular direction, 3.5

- $\mathrm{mm}$ in the dorsal part, $3.0 \mathrm{~mm}$ in the middle, and $2.0 \mathrm{~mm}$ in the ventral part. At the junction with the common bundle the node became more ovoid on transverse sections. The common bundle, which was defined as the

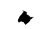

FIG. 2 Magnified view of the $A V$ node region, corresponding to the area indicated by the white arrow in Fig. I. After histological identification on serial sections of the arterial vasculature (see text) and determination of its topographical relation to the conductive tissue, the borders of the AV node and the common bundle (stippled area) have been transferred to this angiogram. A three-dimensional visualization may be obtained by comparing

- the angiogram with the location of the arteries in the 4 vertical sections shown in the lower - part of the Fig. $A, B$, and $C$ represent median sections in the dorsal, middle, and ventral third of the $A V$ node. $E$ is situated in the middle of the common bundle. The ramus septi fibrosi is seen to originate from the top of the

- U-turn (visible at the left margin of the angiogram) of the right circumflex coronary

- artery. It penetrates into the dorsal part of the node. In the middle of the node it makes a 60

- degrees caudal turn and leaves the conductive tissue. Only a small side branch is seen to continue the original course towards the com-

- mon bundle. The scarcity of arteriolar vasculature in the ventral part of the node $(C)$ and , the common bundle $(E)$ contrasts with the larger surface occupied by arterial lumina in

$\lambda$ the dorsal and middle sections of the $A V$ node ( $A$ and $B)$. This characteristic vascular

- arrangement was found in 7 of the Io hearts examined. portion of the AV conducting system situated between the end of the node and the first strands of the left bundle-branch, was relatively short $(1.75 \mathrm{~mm})$. This figure is at variance with results obtained by other workers who, after dissecting the bundle, made macroscopical measurements and included more ventral parts of the system, comprising the entire base of the left branch fascicles and even part of the right bundle (Verduyn Lunel, 1964).

The region of the AV node was supplied by the ramus septi fibrosi which, in all ro hearts, originated from the right circumflex

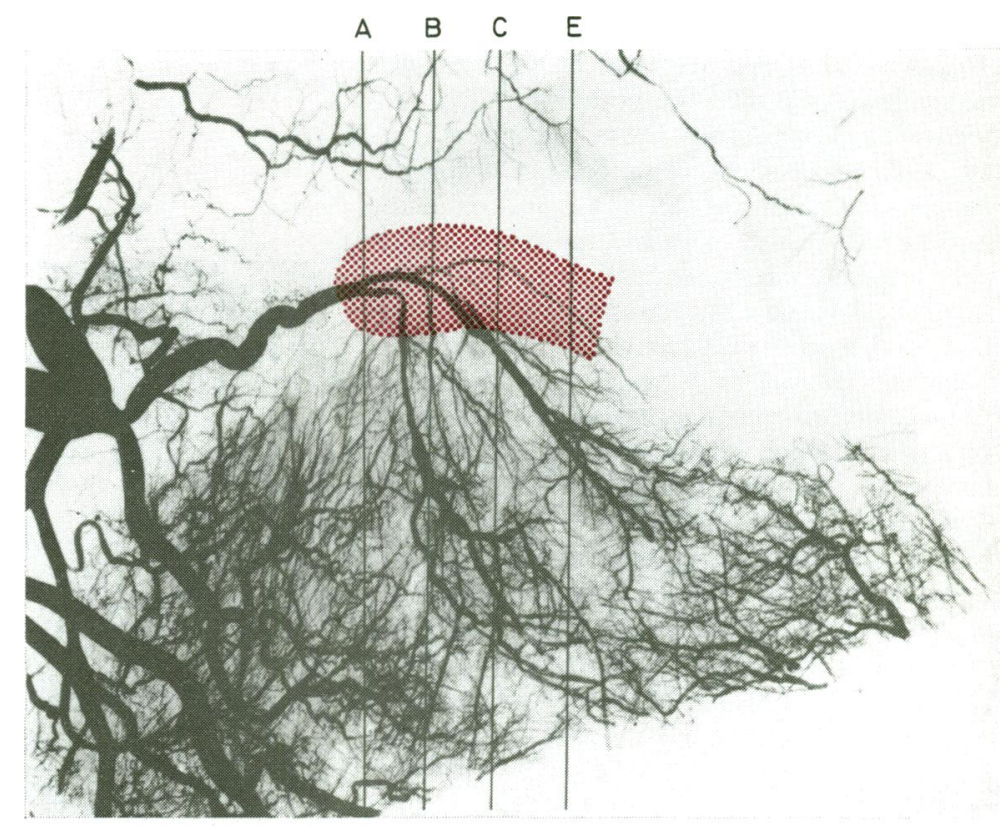

A

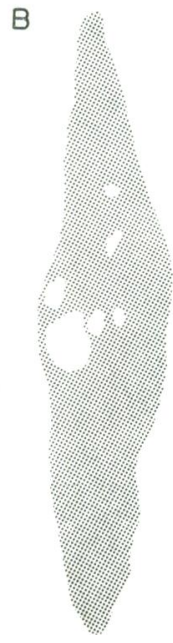


coronary artery. On the specimens and $x$-ray films the latter was usually seen to make a U-loop, the convexity of which was directed ventrally. The U-loop was situated near the dorsal crus of the heart formed by the junction of the atrioventricular groove and the interatrial and interventricular septa. The ramus septi fibrosi arose from the top of the U-loop and coursed in a ventral direction towards the coronary sinus and the AV node. The mean internal diameter, measured on histological sections, was $682 \mu \mathrm{m}$ at the origin on the U-loop and $403 \mu \mathrm{m}$ before penetration into the node. The average length of the artery between these two points was $15.5 \mathrm{~mm}$.

The course and ramifications of the artery inside the node were studied on serial histological sections and reconstructive drawings as described above. In 7 out of ro hearts the artery itself supplied the node in a fairly uniform way. It penetrated into the dorsal margin and, for a short distance, ran a straight course. In the dorsal third ( 3 cases) or in the middle of the node ( 4 cases), the artery invariably made a sharp caudal turn (50 to 90 degrees), left the conducting tissue, and ramified further in the adjacent myocardium (Fig. $I$ and 2). In 4 of the 7 hearts the ramus septi fibrosi, before making this sharp turn, gave off a small branch which continued the original course in the longitudinal axis of the node towards the main bundle. In 3 hearts (No. 5, 6 , and 7) a different pattern was found. The ramus septi fibrosi ran towards the dorsal side of the node but bent into a cranial ( 2 cases) or caudal (I case) direction before reaching it (Fig. 3). Only a side branch entered the node and followed approximately the same course as the ramus septi fibrosi itself in the previous cases, i.e. it made a sharp caudal turn approximately in the middle of the node and penetrated again into the adjacent myocardium. In none of the Io hearts did the ramus septi fibrosi or its main branch supplying the AV conducting system reach the most ventral third of the node or the common bundle. The latter was supplied by a few small arterioles only.

FIG. 3 Angiogram of the $A V$ node region. The ramus septi fibrosi runs a dorso-ventral and slightly upward course. Before reaching the $A V$ node (stipled area) it deviates in a cranial direction. Only two side branches penetrate into the conductive tissue. They make a caudal bend in the middle of the node. $A$ similar pattern of arterial blood supply, in which the ramus septi fibrosi itself did not penetrate into the node, was seen in 3 hearts.
TABLE Arterial density` within $A V$ node and common bundle

\begin{tabular}{|c|c|c|c|c|}
\hline \multirow{2}{*}{$\begin{array}{l}\text { Case } \\
\text { No. }\end{array}$} & \multicolumn{3}{|l|}{$A V$ node } & \multirow{2}{*}{$\begin{array}{l}\text { Common bundle } \\
\text { (mean value } \\
3 \text { sections) }\end{array}$} \\
\hline & Dorsal third & Middle third & Ventral third & \\
\hline I & $16 \cdot 4$ & $7 \cdot 4$ & $5 \cdot 6$ & - \\
\hline 2 & $20 \cdot 9$ & $23 \cdot 0$ & $8 \cdot 2$ & $2 \cdot 7$ \\
\hline 3 & $2 I \cdot 6$ & $12 \cdot 7$ & 4.4 & 0.7 \\
\hline 4 & $16 \cdot 4$ & $15 \cdot 2$ & $I \cdot 7$ & 0.7 \\
\hline 5 & $22 \cdot I$ & I $8 \cdot 8$ & $2 \cdot 4$ & $2 \cdot 2$ \\
\hline 6 & $19 \cdot 0$ & $7 \cdot 8$ & $2 \cdot 3$ & $2 \cdot 4$ \\
\hline 7 & $9 \cdot 2$ & $8 \cdot 5$ & $8 \cdot 3$ & 0.5 \\
\hline 8 & $5 \cdot 8$ & $5 \cdot 7$ & $4 \cdot I$ & $1 \cdot 8$ \\
\hline 9 & $8 \cdot 3$ & 6.9 & $6 \cdot 7$ & $3 \cdot 8$ \\
\hline IO & $4 \cdot 8$ & II 3 & $8 \cdot 6$ & 0.3 \\
\hline Mean & $14 \cdot 4$ & II $\cdot 7$ & $5 \cdot 2$ & $I \cdot 5$ \\
\hline
\end{tabular}

* Percentage of the cross-sectional area of the AV node and common bundle occupied by arterial or arteriolar lumina. Only the lumina of large arterioles, with an internal diameter of at least $20 \mu \mathrm{m}$, were filled by contrast material and measured planimetrically.
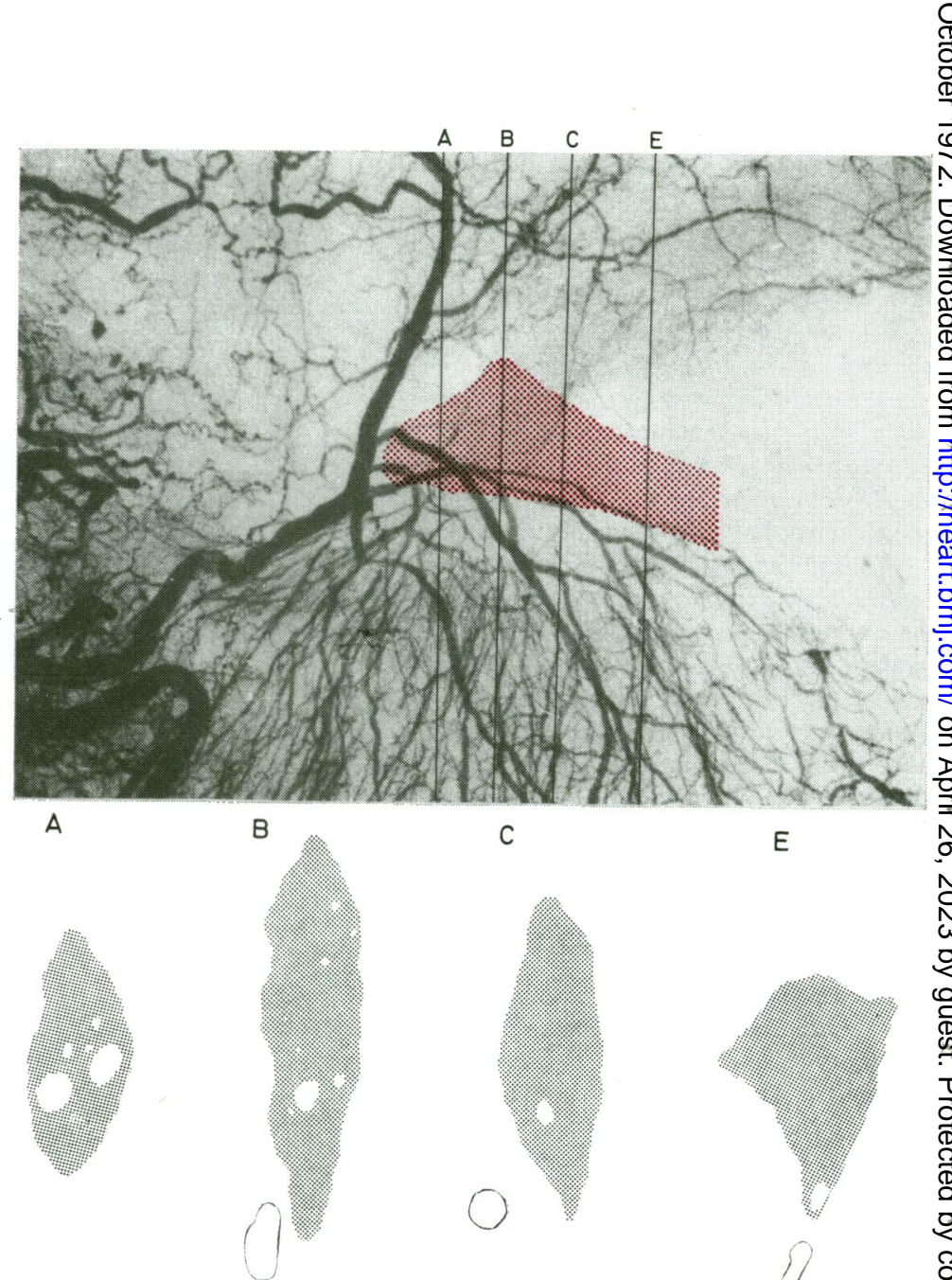
Planimetric studies on transverse sections, cut in atrioventricular direction, further substantiated these findings (Table). In the dorsal

s sections of the node the summed-up crosssectional areas of arteries and arterioles occu-

- pied a significantly larger percentage of the total surface of the nodal tissue than in the more ventral parts and in the common bundle. The average percentage was 14.4 per cent in the dorsal third, II 7 per cent in the middle, and 5.2 per cent in the ventral third. In the common bundle an even lower ratio, 1.5 per - cent, was obtained. The latter figure represents the mean value in ro hearts, resulting

2 from 3 planimetric measurements per heart (dorsal, middle, and ventral part of the common bundle).

In 7 other normal hearts, equally with a right-sided origin of the ramus septi fibrosi, only the left coronary ostium was cannulated and injected under controlled pressure. The - coronary arteries were studied on stereoradiographic films. In only 3 of these hearts did the ramus septi fibrosi become faintly opacified via collateral vessels around the apex of the

- heart. In this region small anastomoses connected distal branches of the left anterior

- descending artery with posterior branches of the right coronary artery, from where contrast material was seen to penetrate into the ramus septi fibrosi. In none of the 7 hearts could collateral vessels be shown in the upper

- part of the interventricular septum. The septal branches from the left anterior descending

- artery were always clearly visualized in the ventral part of the interventricular septum but never penetrated as far dorsally as the AV nodal region.

\section{- Discussion}

4 The gross anatomy of the ramus septi fibrosi which supplies the AV node and, in approxim-

- ately 90 per cent of the human hearts, originates from the right coronary artery, has been known for many years (Haas, I9II; Gross, I92I; Campbell, I929). Recently the course of this artery has been studied in more detail - by means of injection and corrosion techniques (James and Burch, I958; James, 1962,

- 1965) or by an injection and dissection method (Romhilt, Hackel, and Estes, 1968). Refer- ences to its course and ramifications inside the node and common bundle, however, are scanty. Only a combination of postmortem coronary arteriography, histological studies, and their integration into three-dimensional reconstructions, make it possible to show the intricate relation between the arterial tree and the specific conductive tissue. This technique has also been used by Harper et al. (1969) to study pathological changes of the coronary arteries in patients with conduction disturbances.

In the normal human heart we found that the course of the ramus septi fibrosi is less constant than that of the sinus node artery and that its anatomical relation to the conductive tissue is much looser. The ramus ostii cavae superioris always enters the spindleshaped sinus node and transverses it in a central location (Verhaeghe and Van der Hauwaert, 1967). The same does not apply to the artery supplying the AV node. In some hearts ( 3 out of 10 ) the ramus septi fibrosi did not penetrate into the node but, before reaching it, veered into a cranial or caudal direction. Where the artery made this bend it gave off a side branch which supplied the node. In the other cases the artery entered the node at its dorsal aspect. In none of the hearts was the artery seen to run a central course in the entire longitudinal axis of the conducting tissue. In all cases, including the 3 hearts in which a side branch of the ramus septi fibrosi was the main supplying vessel, the artery transversed only the dorsal part of the node, invariably made a sharp caudal turn approximately in the middle of the node, and continued its course in the adjacent non-conducting myocardium. Only a small arteriole arising from the main artery at the site of this turn, continued the original course towards the common bundle.

The main result of the present study is the finding that, in contrast to the dorsal part which is profusely vascularized, the ventral third of the AV node and the main bundle as a whole, are poorly vascularized. This difference is distinctly visible on three-dimensional reconstructive drawings (Fig. 2 and 3 ). It is further borne out by planimetric measurements which showed that the percentage of the cross-sectional area of the main bundle and ventral third of the node, occupied by arterial or arteriolar lumina, was $1 \cdot 5$ per cent and 5.2 per cent, respectively. These ratios were significantly lower than the ratio $(14.4 \%)$ obtained in the dorsal part of the node.

Blood supply to the ventral part of the node and common bundle was equally scarce from other sources. The septal arteries of the left anterior descending artery, which supply most of the bundle branches, did not contribute in a substantial way, either directly or via anastomotic channels with the ramus septi fibrosi, to the blood supply of the common bundle. The ventral part of the node and the common bundle may therefore be considered to be an arteriolar 'no man's land' between the territory of the bundle-branches, supplied mainly 
by tributaries of the left coronary artery, and the dorsal part of the AV node supplied by the ramus septi fibrosi, which usually originates from the right coronary artery.

A remote system of collateral circulation was found in 3 of the 7 hearts in which the left coronary artery was injected selectively. In these hearts sizeable anastomoses between the left and right coronary arteries were shown around the apex of the heart and in the apical part of the interventricular septum. As described by Campbell (1929), a few small anastomoses between the ramus septi fibrosi and some atrial coronary arterioles were seen to fill in the region dorsal to the node. Via these communications some opacification of the ramus septi fibrosi could be produced. It is obvious, however, that in the event of a sudden occlusion of the right coronary artery the node itself would benefit more from this collateral circulation, if present, than the main bundle which usually contains only small terminal twigs of the ramus septi fibrosi.

These anatomical studies may shed some light on the incidence and mechanism of acute $\mathrm{AV}$ block. It is generally recognized that posterior or diaphragmatic myocardial infarction is more frequently complicated by AV block than anterior infarction (James and Burch, 1958; Sutton and Davies, 1968). This difference is readily accounted for by the fact that in approximately 85 per cent of the individuals (Romhilt et al., 1968) the right coronary artery supplies the AV node as well as the posterior wall of the left ventricle. More difficult to explain is the clinical observation that the AV block complicating a posterior infarction is less severe and permanent, and has a significantly lower mortality, than an $\mathrm{AV}$ block in association with an anterior infarction (Blondeau, Rizzon, and Lenègre, 196I; Norris, 1969). This observation may be correlated with the pathological finding that an anterior myocardial infarction due to occlusion of the anterior descending coronary artery must be very extensive to cause necrosis of both bundle-branches. The poor prognosis, therefore, may be attributed to the extensiveness of the infarction rather than to the associated block.

Sutton and Davies (1968) noted also that in posterior infarction complicated by AV block minor damage only was seen in the conductive tissue and that it was usually found in the bundle and not in the AV node. In the vast majority of cases the AV node proper had a normal aspect. On the basis of the present findings an explanation for this difference in vulnerability may be offered. If the ventral portion of the node and particularly the main bundle are poorly vascularized, as has been shown, one may speculate that an acute occlusion or narrowing somewhere in the right coronary artery, severe enough to produce myocardial infarction, will considerably lower the perfusion pressure in the ramus septi fibrosi, even if pre-existing small collateral vessels open up. Because it derives its blood supply from few terminal arterioles the main bundle will suffer more from hypoxia and, in a later stage, patchy necrosis than the AV node which has a more direct and profuse blood supply. Major damage or destruction of the AV node occurs if the ramus septi fibrosi itself becomes occluded which, however, is a very exceptional event (Blondeau et al., I96I; Sutton and Davies, 1968).

The authors gratefully acknowledge the co-operation of Professor J. Bonte, Dr. J. Tombeur, Mrs. M. Hammerle-Massaer, and Miss B. Schotsmans.

\section{References}

Blondeau, M., Rizzon, P., and Lenègre, J. (196I). Les troubles de la conduction auriculo-ventriculaire dans l'infarctus myocardique récent. Archives des Maladies du Coeur et des Vaisseaux, 54, 1092.

Campbell, J. S. (1929). Stereoscopic radiography of the coronary system. Quarterly fournal of Medicine, 22, 247.

Clarke, J. A. (1965). An X-ray microscopic study of the arterial supply to the conducting system of the human heart. British Heart fournal, 27, 879.

Gross, L. (1921). The Blood Supply to the Heart. Paul B. Hoeber, New York.

Haas, G. (I9II). Ueber die Gefässversorgung des Reizleitungssystems des Herzens. Anatomische Hefte, 43, 627.

Harper, J. R., Harley, A., Hackel, D. B., and Estes, E. H. (I969). Coronary artery disease and major conduction disturbances. American Heart fournal, 77, 4II.

James, T.N. (1962). A useful landmark for interpreting angiocardiograms. Radiology, 79, 804 .

James, T. N. (1965). Anatomy of the coronary arteries in health and disease. Circulation, 32, 1020.

James, T. N. (1969). Pathogenesis of arrhythmias in acute myocardial infarction. American fournal of Cardiology, 24, 791.

James, T. N., and Burch, G. E. (1958). The atrial coronary arteries in man. Circulation, 17, 90.

Keith, A., and Flack, M. W. (1906). The auriculoventricular bundle of the human heart. Lancet, 2, 359.

Mönckeberg, J. G. (1908). (Cited by Haas, I9II.)

Norris, R. M. (1969). Heart block in posterior and anterior myocardial infarction. British Heart fournal, 31, 352.

Romhilt, D. W., Hackel, D. B., and Estes, E. H. (1968). Origin of blood supply to sinoauricular and atrioventricular node. American Heart fournal, 75, 279. 
Sutton, R., and Davies, M. (1968). The conduction system in acute myocardial infarction complicated by heart block. Circulation, 38, 987.

Verduyn Lunel, A. A. (1964). De localisatie van het atrioventriculair geleidingssysteem bij normale harten en aangeboren openingen in het septum cordis (with English summary). Thesis, University of Leiden.
Verhaeghe, L., and Van der Hauwaert, L. (1967). Arterial blood supply of the human sinus node. British Heart fournal, 29, 801 .

Requests for reprints to Dr. Luc Van der Hauwaert, St. Raphael University Clinic, Leuven, Belgium. 